\title{
Proliferación y diferenciación osteogénica de células madre mesenquimales en hidrogeles de plasma sanguíneo humano
}

\author{
Itali M. Linero, Adriana Doncel, Orlando Chaparro \\ Grupo de investigación Biología de Células Madre, Universidad Nacional de Colombia, Bogotá, D.C., Colombia
}

Introducción. La utilización de las células madre mesenquimales en la práctica clínica ha aumentado considerablemente en la última década, ya que juegan un papel favorable en los procesos de reparación y regeneración tisular, siendo la principal herramienta de la terapia celular para el tratamiento de enfermedades que afectan funcionalmente el tejido óseo y cartilaginoso.

Objetivo. Evaluar la proliferación y capacidad de diferenciación osteogénica in vitro de células madre mesenquimales derivadas de tejido adiposo humano en un hidrogel de plasma sanguíneo.

Materiales y métodos. Se obtuvieron células madre mesenquimales a partir de explantes de tejido adiposo humano y se caracterizaron por citometría de flujo; se buscó demostrar su multipotencialidad por su capacidad de diferenciación osteogénica y adipogénica. Se evaluó la proliferación celular y la capacidad de diferenciación osteogénica de las células cultivadas en hidrogeles de plasma sanguíneo.

Resultados. Las células madre mesenquimales derivadas de tejido adiposo cultivadas en el hidrogel de plasma sanguíneo humano mostraron un patrón de proliferación muy similar al de las células cultivadas en monocapa y, además, mantuvieron su capacidad de diferenciación hacia el linaje osteogénico.

Conclusiones. El hidrogel de plasma sanguíneo humano es un soporte adecuado para que las células madre mesenquimales derivadas de tejido adiposo humano proliferen y se diferencien hacia el linaje osteogénico y constituye un vehículo adecuado para su administración en regeneración del tejido óseo.

Palabras clave: células madre, hidrogeles, plasma, regeneración ósea.

doi: http://dx.doi.org/10.7705/biomedica.v34i1.1465 Proliferation and osteogenic differentiation of mesenchymal stem cells in hydrogels of human
blood plasma

Introduction: The use of mesenchymal stem cells in clinical practice has increased considerably in the last decade because they play a supporting role in the processes of tissue repair and regeneration, becoming the main tool of cell therapy for the treatment of diseases functionally affecting bone and cartilage tissue.

Objective: To evaluate in vitro the proliferative and osteogenic differentiation ability of mesenchymal stem cells derived from human adipose tissue in a blood plasma hydrogel.

Materials and methods: Mesenchymal stem cells were obtained from human adipose tissue explants and characterized by flow cytometry. Their multipotentiality was demonstrated by their ability to differentiate to adipogenic and osteogenic lineages. Cell proliferation and osteogenic differentiation ability of the cells cultured in blood plasma hydrogels were also evaluated.

Results: Mesenchymal stem cells derived from human adipose tissue growing in human blood plasma hydrogels showed a pattern of proliferation similar to that of the cells cultured in monolayer and also maintained their ability to differentiate to osteogenic lineage.

Conclusions: Human blood plasma hydrogels are a suitable support for proliferation and osteogenic differentiation of mesenchymal stem cells derived from human adipose tissue and provides a substrate that is autologous, biocompatible, reabsorbable, easy to use, potentially injectable and economic, which could be used as a successful strategy for the management and clinical application of cell therapy in regenerative medicine.

Key words: stem cells, hydrogels, plasma, bone regeneration.

doi: http://dx.doi.org/10.7705/biomedica.v34i1.1465

\section{Contribución de los autores:}

Itali M. Linero: diseño de experimentos, obtención, cultivo y caracterización de las Ad-MSC, elaboración del hidrogel de plasma sanguíneo humano, escritura y revisión del manuscrito.

Adriana Doncel: obtención, cultivo y caracterización de las Ad-MSC, y revisión del manuscrito.

Orlando Chaparro: diseño de experimentos, escritura y revisión del manuscrito. 
La utilización de las células madre en la práctica clínica ha aumentado considerablemente en la última década. Durante este tiempo, la comunidad científica ha tratado de comprender los mecanismos biológicos que pueden jugar un papel favorable en los procesos de reparación y regeneración tisular y proyectar su potencialidad en la terapia celular y la medicina regenerativa $(1,2)$.

Los tejidos adultos maduros mantienen una reserva de células madre adultas; en este grupo encontramos las células madre mesenquimales que desde la década de los 70 han sido motivo de múltiples investigaciones, primero por su papel como parte del estroma hematopoyético, y en los últimos 10 años, como una opción terapéutica para múltiples enfermedades por sus propiedades biológicas aplicables al campo de la medicina regenerativa $(3,4)$.

Las células madre mesenquimales son células adultas multipotentes, capaces de autorrenovarse y diferenciarse a linajes mesenquimales como el osteogénico, condrogénico, adipogénico y miogénico, aunque también se ha demostrado su capacidad de diferenciarse a células de origen no mesenquimal como las del tejido nervioso (5-8).

Tradicionalmente la médula ósea se ha considerado como la fuente principal para el aislamiento de las células madre mesenquimales (7), aunque conforman tan solo el $0,001-0,01 \%$ de la población total de las células nucleadas de la médula ósea (9). En diversos estudios se ha demostrado que las células madre mesenquimales pueden ser aisladas a partir de otras fuentes como la sangre del cordón umbilical, sangre periférica (10), tejido adiposo (1113), folículo capilar (14), ligamento periodontal (15) y pulpa dental (16), entre otros.

Dado su importante potencial terapéutico, y con el fin de comparar los resultados de los diversos estudios, la International Society for Cellular Therapy (ISCT) ha propuesto tres criterios mínimos para definir las células madre mesenquimales humanas. El primero corresponde a la capacidad de adherencia al plástico en condiciones de cultivo estándar; el segundo, al fenotipo celular determinado idealmente por citometría de flujo en

Correspondencia:

Orlando Chaparro, Universidad Nacional de Colombia, Ciudad Universitaria, edificio 471, oficina 410, Bogotá, D. C., Colombia

Teléfono: (571) 316 5000, extensión 15059

ochaparrog@unal.edu.co

Recibido: 28/11/12; aceptado: 22/08/13 la que las células madre mesenquimales deben expresar CD105, CD73 y CD90, y no expresar CD45, CD34, CD14, entre otros antígenos hematopoyéticos, y el tercero, que hace referencia a la capacidad de diferenciarse in vitro a los linajes osteogénico, condrogénico y adipogénico $(6,7,17)$.

La información científica respalda el uso de las células madre mesenquimales como una terapia biológica para diversas aplicaciones clínicas por su facilidad de acceso y aislamiento, gran potencial de expansión en cultivo, plasticidad, capacidad de migrar hacia los tejidos lesionados (18), efecto paracrino, propiedades inmunomoduladoras (3,7,19-22), propiedades antiapoptóticas y antifibróticas (6), por su capacidad de promover angiogénesis, producir múltiples tipos de tejido conectivo y disminuir la respuesta inflamatoria (1); además, los trabajos con las células madre mesenquimales no involucran los dilemas éticos que se presentan con el manejo de las células madre embrionarias $(3,6,19)$. Por todo esto, las células madre mesenquimales son hoy en día el centro de múltiples estudios clínicos para ciertas entidades como infarto del miocardio, diabetes, alteraciones cerebrales y de médula espinal, enfermedades cardiovasculares, enfermedad de injerto contra huésped, enfermedad de Crohn $(1,6)$ y otras que involucran el tejido óseo y cartilaginoso $(8,12,23-25)$.

Según los National Institutes of Health $(\mathrm{NIH})$ de los Estados Unidos, a la fecha se están realizando a nivel mundial 340 ensayos clínicos de aplicación de células madre mesenquimales, de los cuales, 195 incluyen enfermedades relacionadas con el tejido muscular, óseo y cartilaginoso como, por ejemplo, la osteoartritis, la osteogénesis imperfecta, la artritis y las enfermedades óseas metabólicas y del desarrollo, entre otras (26).

La fibrina se ha utilizado en medicina desde hace casi 100 años $(27,28)$. Se introdujo en el campo de la cirugía debido a su potencial para actuar como un sellador y ayudante de la hemostasis $(27,29)$. En 1990, Gibble y Ness (30) introdujeron por primera vez la fibrina autóloga, encontrando en ella la capacidad de crear grandes cantidades de gel en corto tiempo, a un bajo costo y con un bajo riesgo de transmisión de enfermedades, lo que popularizó el uso de geles de fibrina de sangre autóloga como un mecanismo de transporte de factores de crecimiento y como una matriz para el trasplante autólogo de células (28). Se han descrito diferentes preparaciones de hidrogeles de fibrina 
para el cultivo y crecimiento de distintos tipos celulares como, por ejemplo, condrocitos para el desarrollo de tejido cartilaginoso (31), fibroblastos y queratinocitos para piel (32), células madre embrionarias (33) y células madre mesenquimales para el desarrollo de tejido óseo $(34,35)$. El hidrogel de fibrina es probablemente uno de los más completos derivados del plasma sanguíneo en términos de su composición y aplicación clínica, que permite la formación de un coágulo semirrígido que es de fácil consolidación y adherencia en el sitio de la aplicación (36-38).

Los defectos óseos y del cartílago son importantes causas de incapacidad funcional y la restauración de la función esquelética, en el campo de la ortopedia y la cirugía maxilofacial, continúa siendo un reto importante. La reparación de defectos óseos que se producen por trauma, tumores, infecciones, trastornos bioquímicos o de desarrollo esquelético anormal son situaciones clínicas que requieren una intervención quirúrgica. Los tipos de material disponible para el tratamiento de estos problemas incluyen hueso autólogo (del mismo paciente), hueso heterólogo (de un donante), matrices desmineralizadas, así como una amplia gama de biomateriales sintéticos como metales, cerámicas, polímeros y materiales compuestos (39-41).

El uso de injertos óseos en la práctica clínica presenta varios inconvenientes como la escasez de donantes, la transmisión de enfermedades, la morbilidad del sitio de extracción y la incapacidad de los materiales para remodelarse y reaccionar ante condiciones fisiológicas, con un alto porcentaje de pérdida por complicaciones como la falta de unión, la reabsorción osteoclástica, el incremento en la prevalencia de microfracturas y la disminución en la densidad mineral ósea (42).

Para reducir tales problemas, la ingeniería de tejidos se ha convertido en una estrategia encaminada a reparar, reconstruir o regenerar tejido vivo utilizando células y biomoléculas en una matriz tridimensional para la formación y el crecimiento de los nuevos tejidos a ser empleados en la reconstitución morfológica y funcional del tejido perdido (43-47).

Con el fin de desarrollar un modelo para la aplicación clínica de las células madre mesenquimales en lesiones óseas, se evaluó su proliferación y capacidad de diferenciación osteogénica in vitro en un hidrogel de plasma sanguíneo humano. El hidrogel de plasma sanguíneo proporcionaría un soporte autólogo, totalmente biocompatible, reabsorbible, de fácil manejo, potencialmente inyectable y económico, en el que las células madre mesenquimales cumplen su papel de regeneración y reparación del tejido óseo afectado, lo que podría llegar a ser una estrategia exitosa en la búsqueda de una nueva alternativa para su administración y aplicación clínica en medicina regenerativa.

\section{Materiales y métodos}

\section{Obtención y cultivo de las células madre mesenquimales derivadas de tejido adiposo humano}

Las muestras para el estudio se obtuvieron a partir de biopsias de tejido adiposo humano de dos individuos mayores de edad (23 y 35 años) de sexo femenino, programados para cirugía máxilo-facial, de quienes se obtuvo la aprobación y la firma del consentimiento informado; se contó con el aval del Comité de Ética de la Facultad de Medicina de la Universidad Nacional de Colombia.

Se sembraron explantes de, aproximadamente, 0,2 cm de diámetro de tejido adiposo en cajas plásticas de cultivo de seis pozos (cajas GreinerBio-one), y medio de cultivo Dulbecco's Modified Eagle ${ }^{T M}$ bajo en glucosa (DMEM, GIBCO), con suplemento de 10 $\%$ de suero fetal bovino (SFB ${ }^{\mathrm{TM}}$, GIBCO), penicilina $100 \mathrm{U} / \mathrm{ml}$ y estreptomicina $100 \mu \mathrm{g} / \mathrm{ml}$. Los explantes se incubaron a $37^{\circ} \mathrm{C}$ en atmósfera húmeda con 5 $\%$ de $\mathrm{CO}_{2}$. El medio fue reemplazado por medio de cultivo fresco dos veces por semana hasta que las células alcanzaron $70-80 \%$ de confluencia entre la segunda y la tercera semana de cultivo (48).

\section{Caracterización de las células madre mesenquimales derivadas de tejido adiposo humano por citometría de flujo}

Las células madre derivadas de tejido adiposo (Ad-MSC) de sexto pasaje en $70 \%$ de confluencia fueron recolectadas con tripsina al $0,25 \%$ (GIBCO), llevadas a una concentración de 5 $x 10^{5}$ e incubadas con anticuerpo monoclonal anti-CD105 humano-PE (Phycoerytrin ${ }^{\mathrm{TM}}$, clon sn6, eBioscience), anticuerpo monoclonal antiCD34 humano-APC (Allophicocyanin ${ }^{\mathrm{TM}}$, clon AC 136, Milteny Biotec), anticuerpo monoclonal anti-CD45 humano-RPE-Cy5 (R-phycoerytrinCyanine $5^{\mathrm{TM}}$, clon T29/33, Dako Cytomation), anticuerpo monoclonal anti-CD 90 humano-APC (Allophicocyanin, Alexa Fluor ${ }^{\mathrm{TM}}$, clon F 15-42-1, AbD, Serotec), anticuerpo monoclonal anti-HLAABC humano-FITC (Fluorescein Isothiocyanate ${ }^{\mathrm{TM}}$, 
clon w6/332,AbD, Serotec), anticuerpo monoclonal anti-HLA-DR humano-RPE (R-Phycoerytrin ${ }^{\mathrm{TM}}$, clon $A B / 3$ ), y los controles negativos específicos de isotipo IgG1/RPE Cy5, IgG2a/RPE e IgG1/FITC (Dako Cytomation).

Las lecturas y el análisis de resultados se realizaron en el citómetro FACS Canto ${ }^{\mathrm{TM}}$ ubicado en la Unidad de Citometría de Flujo del Departamento de Farmacia de la Universidad Nacional de Colombia.

Se adquirieron, aproximadamente, 10.000 eventos de la región que corresponde a una población celular con alta complejidad (sidescatter) y tamaño (forward scatter) y se realizó el análisis de esta población para observar la expresión de los antígenos CD34, CD45, CD105, CD90, HLA-ABC y HLA-DR independientemente.

\section{Diferenciación osteogénica}

Las células se incubaron en medio de diferenciación osteogénica: DMEM con suplemento de $10 \%$ de SFB, penicilina $100 \mathrm{U} / \mathrm{ml}$, estreptomicina $100 \mu \mathrm{g} /$ $\mathrm{ml}$, dexametasona $0,1 \mu \mathrm{M}$, ascorbato-2-fosfato $50 \mu \mathrm{M}$ y a-glicerol fosfato $10 \mathrm{mM}$ (Sigma-Aldrich) $(49,50)$. El medio de inducción se reemplazó dos veces por semana durante tres semanas, incubando las células a $37^{\circ} \mathrm{C}$ en atmósfera húmeda con $5 \%$ de $\mathrm{CO}_{2}$. Como control negativo se usaron células incubadas en medio de cultivo convencional y todos los ensayos se realizaron por triplicado.

A la primera semana de inducción se evalúo la actividad de la enzima fosfatasa alcalina, un marcador temprano de diferenciación osteogénica, mediante la tinción de Fast Red (Sigma-Aldrich) (51). Además, a las tres semanas de incubación con el medio de inducción las células se tiñeron para detectar depósitos de calcio utilizando la tinción de von Kossa (Sigma-Aldrich) (3).

\section{Diferenciación adipogénica}

Los cultivos celulares de sexto pasaje se incubaron durante tres semanas en medio de inducción adipogénica: DMEM con alto contenido de glucosa, con suplemento de $10 \%$ de SFB, penicilina 100 $\mathrm{U} / \mathrm{ml}$, estreptomicina $100 \mu \mathrm{m} / \mathrm{ml}$, indometacina $100 \mu \mathrm{M}$, insulina $10 \mu \mathrm{g} / \mathrm{ml}$, isobutil-metilxantina $0,5 \mathrm{mM}$ y dexametasona $1 \mu \mathrm{M}$ (49). Se utilizaron células cultivadas en medio convencional como control negativo. Para evidenciar la diferenciación adipogénica, las inclusiones citoplasmáticas de lípidos se colorearon con aceite rojo O (SigmaAldrich) (52).

\section{Elaboración del hidrogel de plasma sanguíneo humano}

Los hidrogeles de $250 \mu \mathrm{l}$ se prepararon mezclando plasma sanguíneo humano $(83 \mu \mathrm{l})$, solución salina estéril $(133 \mu \mathrm{l})$, ácido tranexámico $100 \mathrm{mg} / \mathrm{ml}(1,6$ $\mu \mathrm{l})$, DMEM $(16,6 \mu \mathrm{l})$ y $\mathrm{CaCl}_{2}$ al $10 \%$ estéril $(16,6$ $\mu \mathrm{l})$. Para el cultivo de las células en los hidrogeles se utilizaron 50.000 Ad-MSCs por hidrogel, resuspendidas en DMEM con suplemento de $10 \%$ de SFB. Las estructuras tridimensionales resultantes, compuestas por Ad-MSC embebidas en los hidrogeles, se cultivaron en DMEM con suplemento de $10 \%$ de SFB, penicilina $100 \mathrm{U} / \mathrm{ml}$, estreptomicina $100 \mathrm{~g} / \mathrm{ml}$ y se incubaron a $37^{\circ} \mathrm{C}$ en atmósfera húmeda con $5 \%$ de $\mathrm{CO}_{2}$. El medio se reemplazó dos veces por semana. Se observaron las características macroscópicas y microscópicas de los hidrogeles, así como la permanencia y proliferación de las Ad-MSC en su interior.

\section{Microscopía electrónica de barrido}

El hidrogel de plasma sanguíneo humano se analizó por microscopía electrónica de barrido para determinar la morfología y porosidad. Los hidrogeles se fijaron en glutaraldehído al $2 \%$, se deshidrataron en etanol y se secaron utilizando el secador de punto crítico para retener la estructura del poro. Posteriormente, las muestras se recubrieron con $\mathrm{Au} / \mathrm{Pd}$ y se procedió a analizarlas al microscopio electrónico de barrido en el Laboratorio de Microscopia Electrónica de Barrido, en el Centro de Equipos Interfacultades de la Universidad Nacional de Colombia (53).

\section{Ensayo de proliferación de las células madre mesenquimales derivadas de tejido adiposo humano}

La proliferación celular se analizó utilizando el Vybrant MTT Cellproliferation Assay Kit ${ }^{\mathrm{TM}}$ (Invitrogen V-13154) y siguiendo las recomendaciones del fabricante.

Para el análisis de proliferación en monocapa, las Ad-MSCs se sembraron en cajas de 96 pozos a una concentración de 10.000 células en $100 \mu \mathrm{l}$ de DMEM con suplemento de $10 \%$ SFB, penicilina $100 \mathrm{U} / \mathrm{ml}$ y estreptomicina $100 \mu \mathrm{g} / \mathrm{ml}$ y se incubaron a $37^{\circ} \mathrm{C}$ en atmosfera húmeda con 5 $\%$ de $\mathrm{CO}_{2}$; se realizaron lecturas entre los días 1 y 12. Las lecturas de la densidad óptica se hicieron en un microlector de platos Ultramark ${ }^{\mathrm{TM}}$ a una longitud de onda de $550 \mathrm{~nm}$. Los datos obtenidos fueron comparados con una curva estándar con concentraciones celulares conocidas. Todos los ensayos se realizaron por triplicado. 
La proliferación de las Ad-MSC en los hidrogeles se evaluó sembrando 50.000 células por hidrogel y haciendo seguimiento hasta el día 16 de cultivo. Se comparó con una curva de calibración en hidrogeles de plasma sanguíneo con diferentes concentraciones celulares de entre 15.000 y 200.000 células. Las lecturas de la densidad óptica se hicieron en un microlector de platos Ultramark ${ }^{\mathrm{TM}}$ a una longitud de onda de $550 \mathrm{~nm}$. Todos los ensayos se realizaron por triplicado.

\section{Diferenciación osteogénica de células madre mesenquimales derivadas de tejido adiposo humano en los hidrogeles de plasma sanguíneo humano}

Los ensayos de diferenciación osteogénica en los hidrogeles de plasma sanguíneo se realizaron como se describió previamente para la caracterización de las Ad-MSC en monocapa. Para el análisis de actividad de la enzima fosfatasa alcalina y la detección de los depósitos de calcio, los hidrogeles se fijaron en paraformaldehído al $4 \%$, se embebieron en parafina, y se hicieron cortes histológicos de $4 \mu \mathrm{m}$. Las láminas fueron teñidas con las coloraciones de von Kossa y de Fast Red (54).

\section{Resultados}

\section{Caracterización de las células madre mesenquimales derivadas de tejido adiposo humano}

Entre la primera y segunda semanas de cultivo se observaron células fibroblastoides adherentes al plástico adyacentes al explante de tejido adiposo. A partir de la tercera semana de cultivo se observaron abundantes células que formaban una monocapa celular confluente que cubría la superficie de la caja de cultivo. Las células aisladas se expandieron en cultivo con tripsina y pasajes seriados (figura 1).

\section{Caracterización por citometría de flujo}

El fenotipo de las Ad-MSC se determinó por citometría de flujo evaluando la expresión de los antígenos de superficie CD105 y CD90 característicos de las células madre mesenquimales, y CD45 y CD34, marcadores característicos hematopoyéticos. Además, se analizó la expresión de HLA-ABC y -HLA-DR. Se adquirieron, aproximadamente, 10.000 eventos de la región que corresponde a una población celular similar en complejidad y tamaño. Se usaron como control las Ad-MSC en cultivo sin marcar. Los resultados, como se observa en la figura 2, mostraron que las células expresaban los antígenos CD105, CD90 y HLA I y no así los CD45, CD34 y HLA II. Este inmunofenotipo concuerda con los parámetros establecidos por la International Society for Cellular Therapy como el perfil característico de las células madre mesenquimales.

\section{Diferenciación osteogénica}

La capacidad de diferenciación ósea se determinó por medio de la detección de la enzima fosfatasa alcalina, marcador temprano del fenotipo osteoblástico, y la mineralización de la matriz extracelular como marcador de la funcionalidad celular.

Después de la primera semana de inducción osteogénica se detectó la presencia de fosfatasa alcalina con la tinción Fast Red en los cultivos celulares tratados con medio de inducción y la ausencia de expresión de esta enzima en las
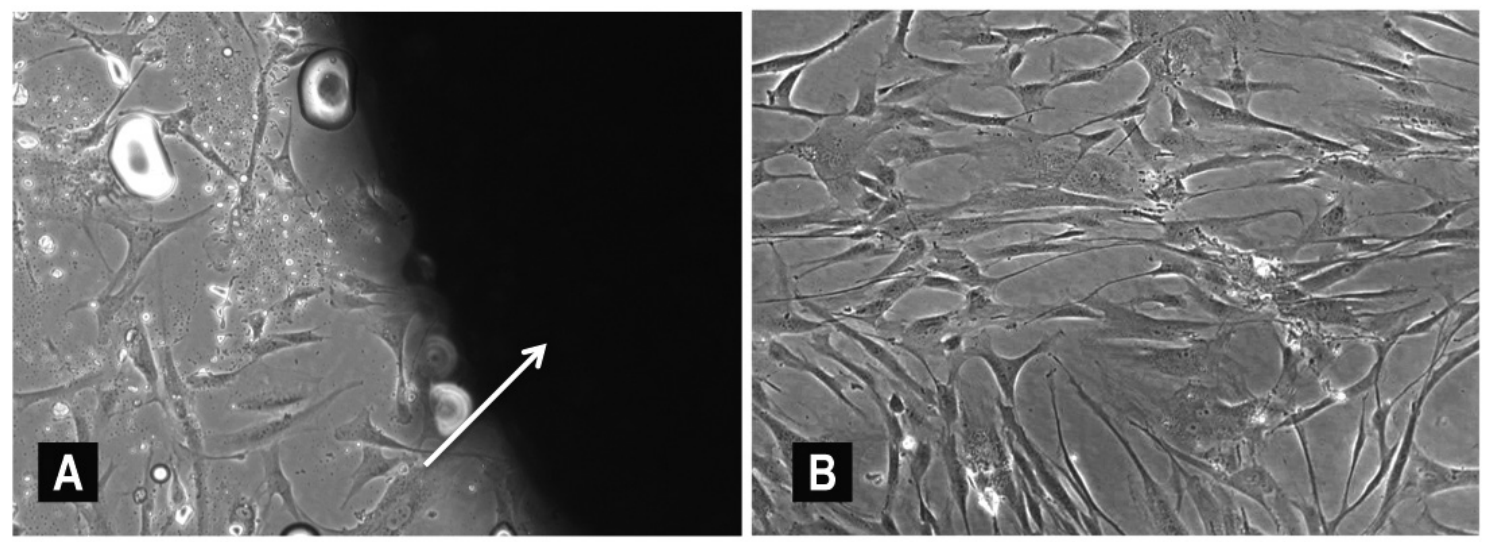

Figura 1. Obtención y cultivo de Ad-MSC a partir de tejido adiposo humano. A. Semana uno de cultivo, se observan células fibroblastoides adyacentes al explante de tejido adiposo (flecha blanca). B. Semanas dos a tres de cultivo, presencia de células fibroblastoides adherentes al plástico con morfología homogénea, 10X. 

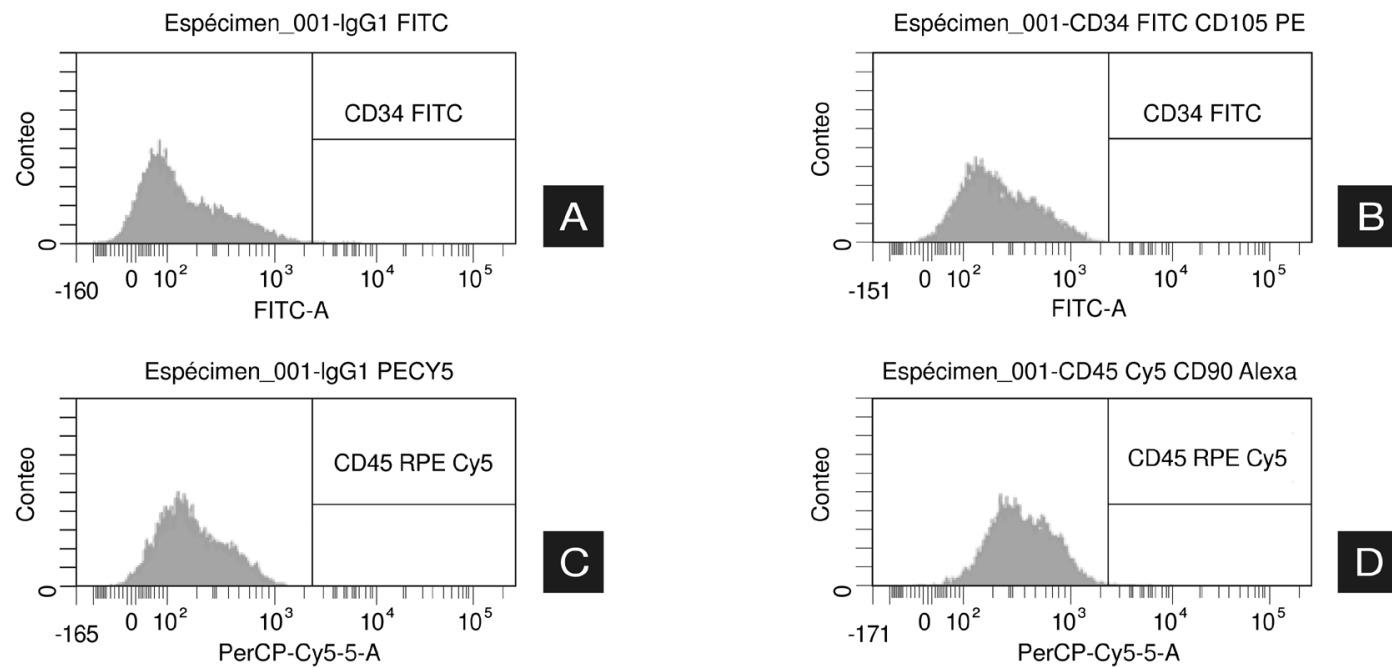

\section{C}

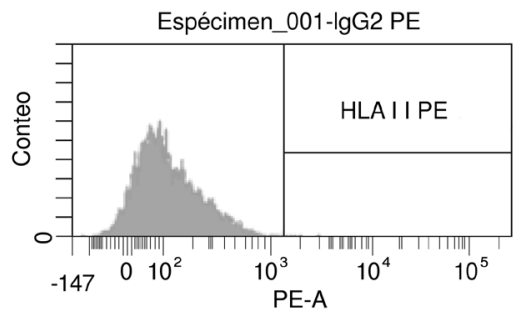

$\mathrm{E}$

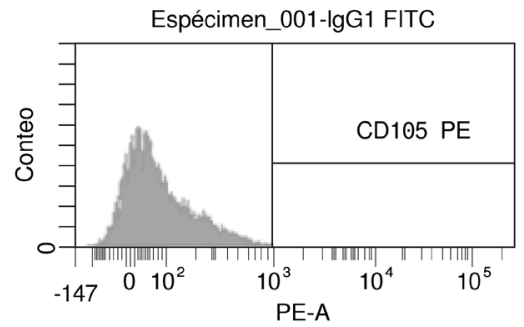

G

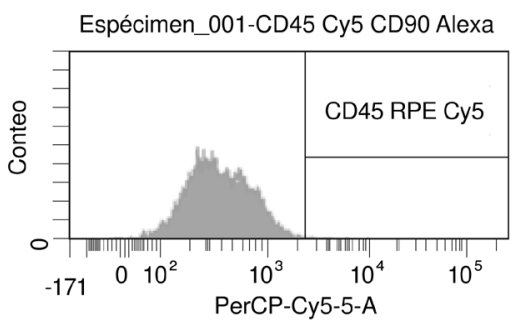

D

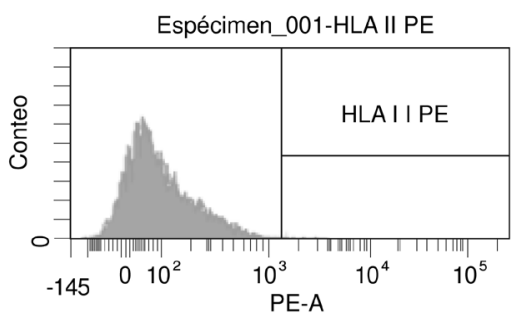

$\mathrm{F}$

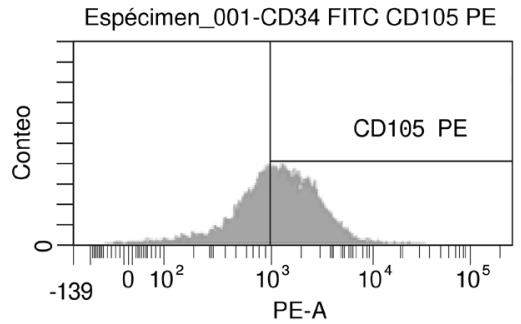

$\mathrm{H}$
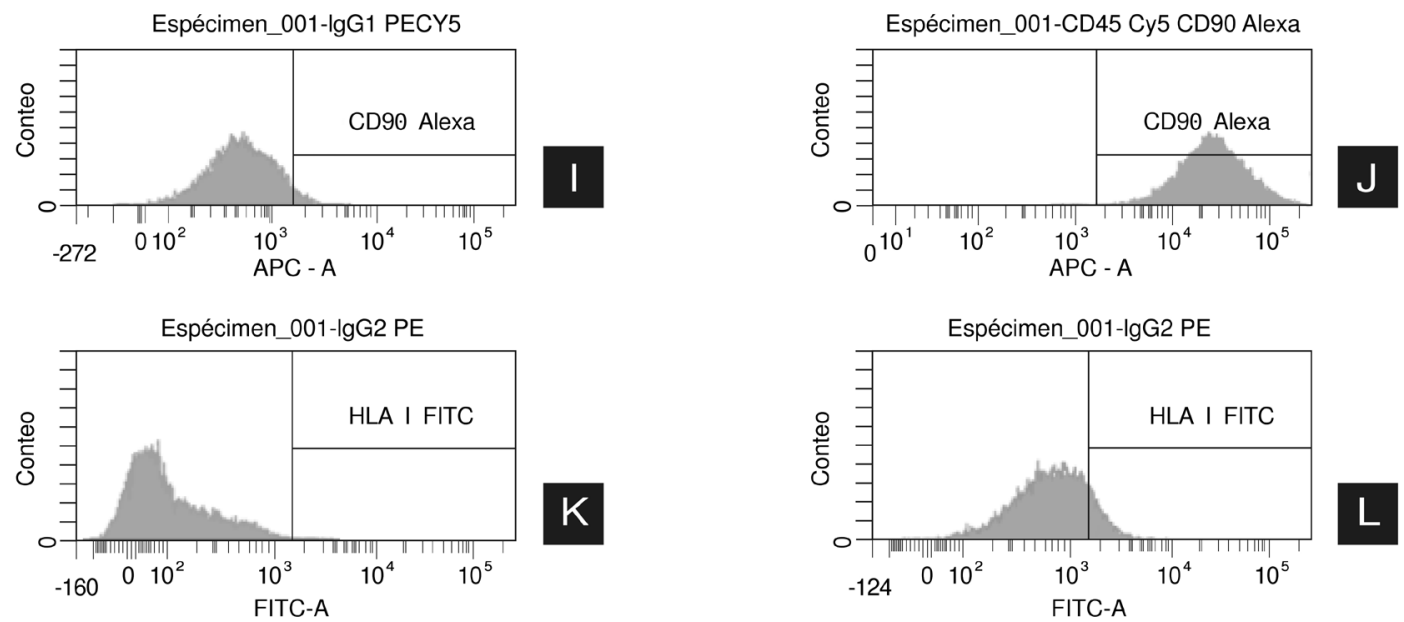

Figura 2. Caracterización de las células Ad-MSC por citometría de flujo. Las células madre mesenquimales obtenidas a partir de tejido adiposo de sexto pasaje y en $70 \%$ de confluencia, se marcaron con anticuerpos monoclonales y se analizaron por citometría de flujo. Podemos observar en la columna de la derecha (A, C, E, G, I y K) los controles de isotipo para cada uno de los marcadores y en la columna de la izquierda, las Ad-MSC. B. Células marcadas con CD34 FITC. D. Células marcadas con CD45-RPECy5. F. Células marcadas con HLA II-RPE. H. Células marcadas con CD105-PE. J. Células marcadas con CD90-Alexa. L. Células marcadas con HLA I-FITC. 
células no inducidas (control) (figura 3, paneles A y B). Después de la tercera semana de cultivo con el medio de inducción osteogénica se observaron los depósitos de mineralización ósea de color café oscuro con la tinción de von Kossa. Las Ad-MSC no inducidas (control) fueron negativas (figura 4, paneles A y B).

\section{Diferenciación adipogénica}

Después de tres semanas del tratamiento con el medio de inducción adipogénica fue evidente la aparición de vacuolas lipídicas (ricas en triglicéridos), lo cual se evidenció con la tinción positiva del aceite rojo $O$ (figura 5 , paneles $A$ y B) mientras que las células no inducidas fueron negativas para esta tinción (figura 5, panel C).

\section{Cultivo de las células madre mesenquimales derivadas de tejido adiposo humano en hidrogeles de plasma sanguíneo humano}

El tiempo de gelificación desde el momento de la adición del $\mathrm{CaCl}_{2}$ fue de tres a cinco minutos, aproximadamente. El hidrogel de plasma sanguíneo humano exhibió una composición homogénea, transparente, sin sedimentos ni turbidez. Estas características permitieron la visualización microscópica de las Ad-MSC durante su proliferación y diferenciación (figura 6). Además, fue de fácil manipulación y permaneció estable durante el estudio. Las células presentaron una morfología fibroblastoide a partir del segundo día de la siembra (figura 6, paneles D, E y F).
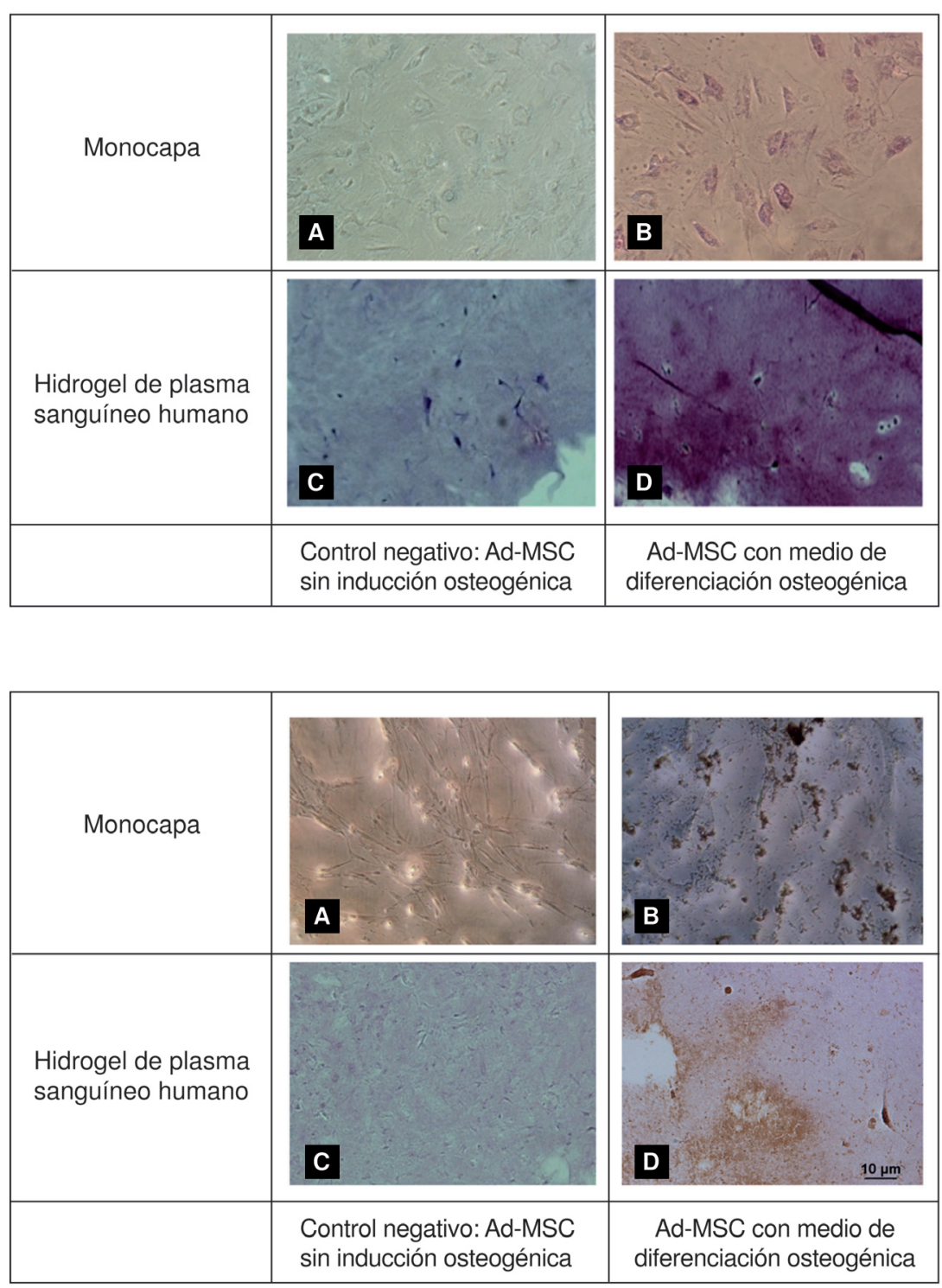

Figura 3. Diferenciación osteogénica de las Ad-MSC. La capacidad de diferenciación ósea se determinó por medio de la detección de la actividad de la enzima fosfatasa alcalina con la tinción Fast Red en la primera semana de cultivo con medio de diferenciación osteogénica. A y B. Ad-MSC en monocapa, 10X. C y D. Ad-MSC en hidrogel de plasma sanguíneo, 40X.

Figura 4. Diferenciación osteogénica de las Ad-MSC. La capacidad de diferenciación ósea se determinó por medio de la detección de depósitos de calcio con la tinción de von Kossa en la tercera semana de cultivo con medio de diferenciación osteogénica. A y B. Ad-MSC en monocapa, 10X. C y D. Ad-MSC en hidrogel de plasma sanguíneo, 40X. 
Mediante microscopía electrónica de barrido se observó que las redes de fibrina formaban una estructura tridimensional que generó un enmallado con poros interconectados entre sí con un diámetro promedio de entre 20 y $30 \mu \mathrm{m}$ (figura 6, paneles B y C).

\section{Ensayo de proliferación celular}

En la figura 7 se presentan las curvas de proliferación celular tanto en monocapa como en los hidrogeles de plasma sanguíneo humano. Los resultados demostraron que el hidrogel proporciona un microambiente adecuado para la proliferación celular.

\section{Diferenciación osteogénica de células madre mesenquimales derivadas de tejido adiposo humano en el hidrogel de plasma sanguíneo humano}

Después de la primera semana de inducción osteogénica se detectó la presencia de fosfatasa alcalina con la tinción Fast Red en los hidrogeles tratados con medio de inducción y la ausencia de expresión de esta enzima en los hidrogeles control (figura 3, paneles $\mathrm{C}$ y $\mathrm{D}$ ). Después de la tercera semana de cultivo con el medio de inducción osteogénica se observaron los depósitos de calcio con la tinción de von Kossa. En las Ad-MSC no inducidas (control) no se observaron los depósitos de calcio (figura 4, paneles $\mathrm{C}$ y D).

\section{Discusión}

La ingeniería de tejidos se ha desarrollado como una estrategia terapéutica para reparar, reconstruir o regenerar tejido vivo. Para lograrlo se requiere no solamente de células reparadoras, sino también de una matriz adecuada que se pueda implantar en el sitio donde está el defecto y sirva de soporte a las células implantadas para que puedan proliferar e interactuar con factores de crecimiento y citocinas específicas (43).

Por su capacidad de diferenciación a múltiples linajes, específicamente por su potencialidad osteogénica y sus propiedades inmunomoduladoras, antiinflamatorias y anti-apoptóticas, las células madre mesenquimales se han convertido en la principal herramienta de la terapia celular para el tratamiento regenerativo de enfermedades que afectan funcionalmente al tejido óseo $(1,3,8,24,55-57)$.

La cantidad y accesibilidad de tejido adiposo subcutáneo en humanos hace que sea una alternativa más atractiva que la médula ósea como fuente de células madre adultas. Los primeros métodos para el aislamiento de las Ad-MSC fueron iniciados por Rodbell y Jones en la década de 1960, quienes por disgregación enzimática aislaron la población de células adherentes de la fracción vascular endotelial. Este procedimiento se ha modificado a lo largo del tiempo. Inicialmente, los fragmentos se trituraban a mano, pero con el desarrollo de la cirugía por liposucción se ha simplificado este primer paso (58). Sin embargo, con este método el proceso de aislamiento requiere de la manipulación de grandes volúmenes de lípidos, lo cual aumenta los riesgos potenciales de contaminación (59). Para facilitar este proceso y disminuir el riesgo de contaminación por otros tipos celulares, en nuestro grupo de investigación se utilizó un método diferente para el aislamiento a pequeña escala (48). La extracción celular a partir del método de explante constituye un procedimiento fácil, de mínima morbilidad y menos invasivo que el método de lipoaspirado y, además, permite
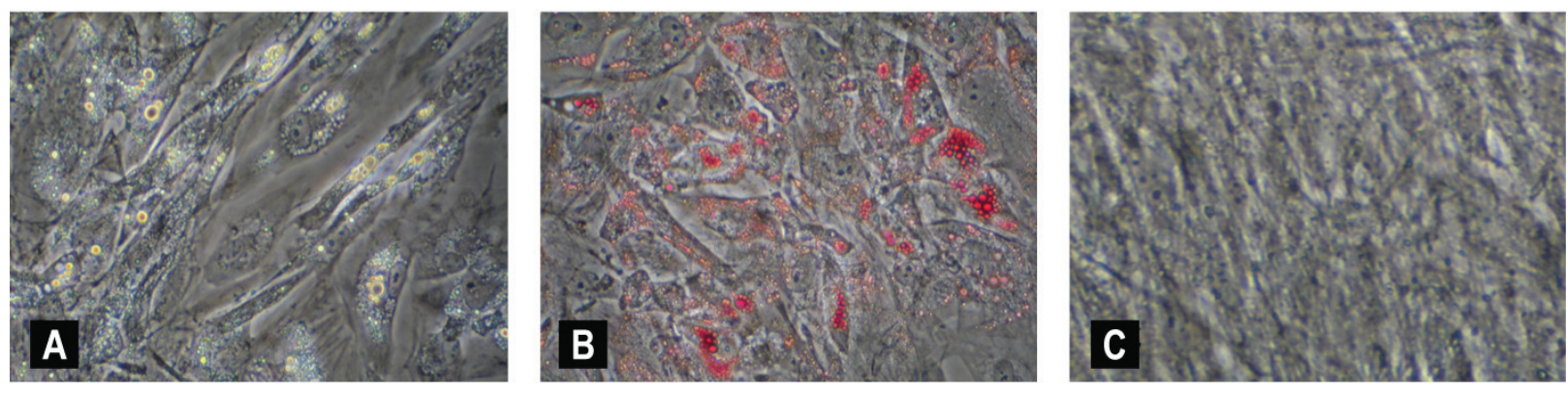

Figura 5. Diferenciación adipogénica de las Ad-MSCs. La capacidad de diferenciación adipogénica se evidenció por medio de la formación de vacuolas lipídicas a las tres semanas de cultivo en medio de inducción adipogénica. A. Presencia de vacuolas lipídicas observadas por microscopía de contraste de fase. B. Vacuolas lipídicas evidenciadas con la tinción aceite rojo O. C. Control negativo, células sin inducción, 40X. 

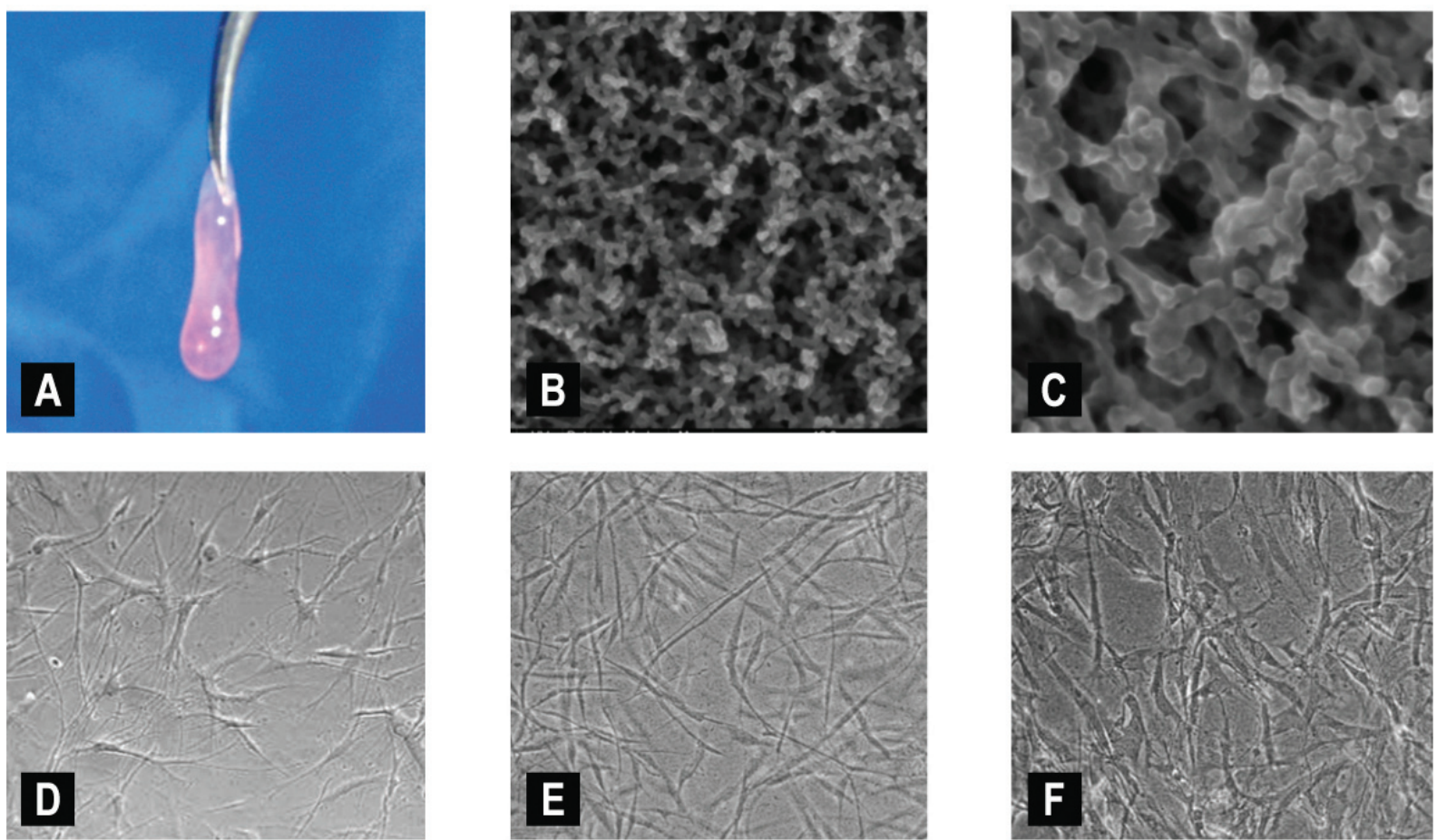

Figura 6. Cultivo de las Ad-MSC en hidrogeles de plasma sanguíneo humano. A. El hidrogel de plasma sanguíneo humano exhibe una composición homogénea, sin sedimentos ni turbidez, transparente y de fácil manipulación. B y C. Microscopía electrónica de barrido: sección representativa del hidrogel de plasma sanguíneo humano en la que se observan las redes de fibrina que forman una estructura tridimensional con poros interconectados entre sí. Se observan las Ad-MSC como pequeños cuerpos redondeados adheridos a las fibras de fibrina. B, 12.000X. C, 25.000X. D, E y F. Microscopía de contraste de fases. D. Día dos de cultivo. E. Día siete de cultivo. F. Día nueve de cultivo, 10X.
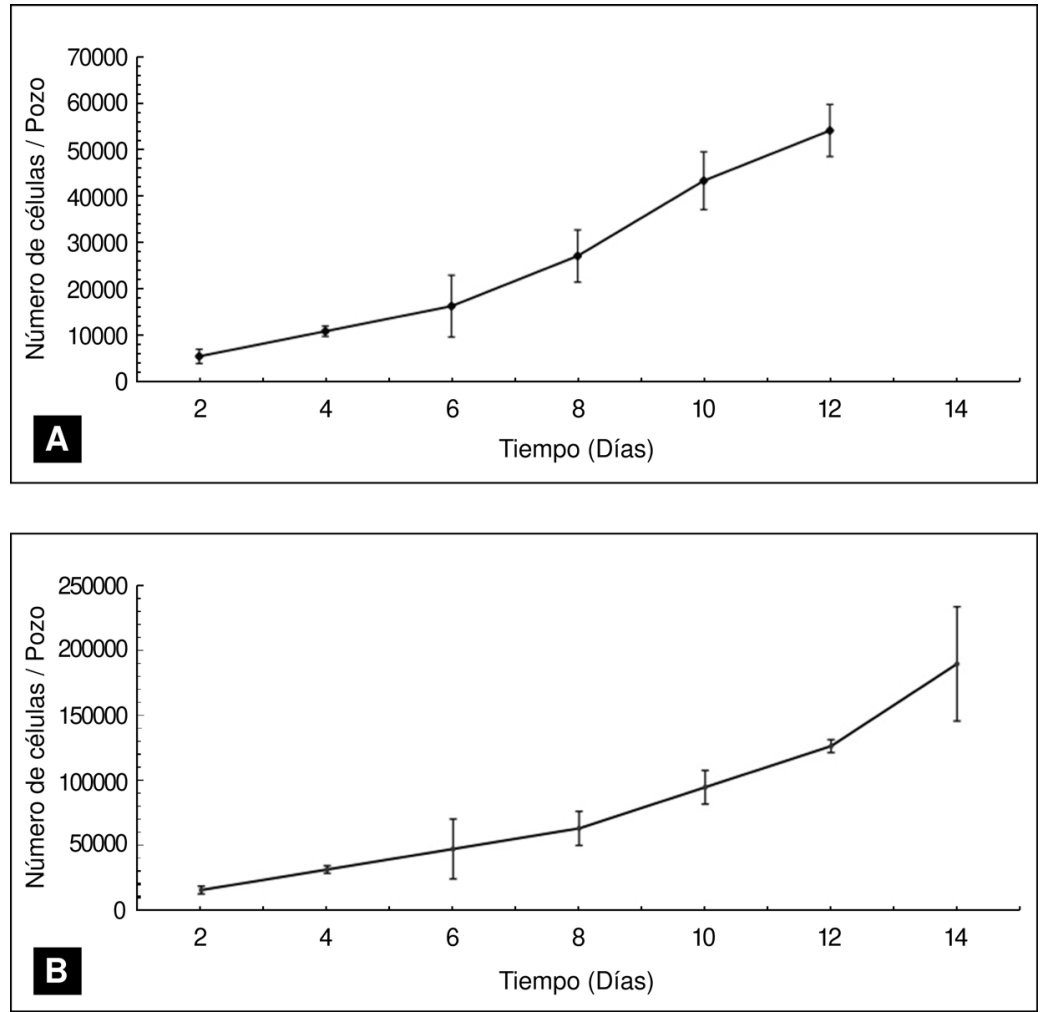

Figura 7. Curvas de proliferación celular. Evaluación de proliferación de Ad-MSC. A. Ad-MSC sembradas en monocapa, B. Ad-MSC sembradas en hidrogeles de plasma sanguíneo humano (media $\pm \mathrm{DE}$ ). 
obtener células que cumplen con los parámetros morfológicos, fenotípicos y funcionales establecidos por la International Society for Cellular Therapy para ser definidas como células madre mesenquimales (18,60-62).

En este estudio, las células madre mesenquimales aisladas de tejido adiposo humano presentaron una forma fibroblastoide (figura 1) y expresaron los marcadores CD105, CD90 y HLA I y no expresaron CD34, CD45 y HLA II (figura 2). Este perfil de expresión coincide con el perfil de marcadores de superficie celular descrito típicamente para las células madre mesenquimales en la literatura $(1,6,9,18,60)$. Además, se demostró que estas células son capaces de diferenciarse hacia el linaje osteogénico y adipogénico, cumpliendo con los parámetros internacionales para ser definidas como células madre mesenquimales.

Nuestros resultados demostraron que las $\mathrm{Ad}$ MSC proliferaron en el interior del hidrogel de plasma sanguíneo humano presentando un patrón de proliferación muy similar al observado en el cultivo en monocapa (figura 7). Esto indica que el hidrogel proporcionó un microambiente adecuado, con un tamaño de poro apropiado (entre 20 y 30 $\mu \mathrm{m}$ ) (figura 6, paneles B y C) para la proliferación celular y que en estas condiciones las Ad-MSC conservaron su capacidad de diferenciación hacia el linaje osteogénico (figuras 3 y 4). Estas dos características son muy importantes para pensar en la utilización de este modelo en terapia celular del tejido óseo, ya que es fundamental que las células conserven su capacidad de proliferación y diferenciación osteogénica en el momento de ser trasplantadas para que respondan adecuadamente a los estímulos generados en el sitio de la lesión.

En cuanto a su aplicación clínica, el hidrogel de plasma sanguíneo humano puede administrase en el sitio del defecto en estado líquido para que se adapte a la forma y tamaño del defecto a tratar. Una vez allí, se gelifica formando una estructura tridimensional que contiene en su interior las células madre mesenquimales y permite que estas células ejerzan su actividad terapéutica. Esta podría llegar a ser una estrategia exitosa en la búsqueda de una alternativa para la administración y aplicación clínica de las células madre mesenquimales en medicina regenerativa.

\section{Agradecimientos}

Este trabajo se realizó gracias al apoyo de la División de Investigaciones de la Universidad Nacional de Colombia, Sede Bogotá, Proyecto Código 5422.

\section{Conflicto de intereses}

Los autores de este manuscrito declaran no tener conflicto de intereses.

\section{Financiación}

El presente trabajo se realizó con recursos de la Dirección de Investigación, sede Bogotá, de la Universidad Nacional de Colombia.

\section{Referencias}

1. Ankrum J, Karp JM. Mesenchymal stem cell therapy: Two stepsforward, onestepback. Trends MolMed.2010;16:203-9. http://dx.doi.org/10.1016/j.molmed.2010.02.005

2. Meirelles LS, Fontes AM, Covas DT, CaplanAI.Mechanisms involved in the therapeutic properties of mesenchymal stem cells. Cytokine Growth Factor Rev. 2009;20:419-27. http:// dx.doi.org/10.1016/j.cytogfr.2009.10.002

3. Zhang X, Tang T, Shi $\mathbf{Q}$, Fernandes JC, Dai K. The immunologic properties of undifferentiated and osteogenic differentiated mouse mesenchymal stem cells and its potential application in bone regeneration. Immunobiology. 2009;214:179-86. http://dx.doi.org/10.1016/j.imbio.2008. 07.030

4. Sethe S, Scutt A, Stolzing A. Aging of mesenchymal stem cells. Ageing Res Rev. 2006;5:91-116. http://dx.doi. org/10.1016/j.arr.2005.10.001

5. Salasznyk RM, Klees RF, Williams WA, Boskey A, Plopper GE. Focal adhesion kinase signaling pathways regulate the osteogenic differentiation of human mesenchymal stem cells. Exp Cell Res. 2007;313:22-37. http://dx.doi. org/10.1016/j.yexcr.2006.09.013

6. Meirelles Lda S, Fontes AM, Covas DT, Caplan Al. Mechanisms involved in the therapeutic properties of mesenchymal stem cells. Cytokine Growth Factor Rev. 2009;20:419-27. http://dx.doi.org/10.1016/j.cytogfr.2009. 10.002

7. Salem HK, Thiemermann C. Mesenchymal stromal cells: Current understanding and clinical status. Stem Cells. 2010;28:585-96. http://dx.doi.org/10.1002/stem.269

8. Krampera M, Pizzolo G, Aprili G, Franchini M. Mesenchymal stem cells for bone, cartilage, tendon and skeletal muscle repair. Bone. 2006;39:678-83. http://dx.doi. org/10.1016/j.bone.2006.04.020

9. Pittenger MF, Mackay AM, Beck SC, Jaiswal RK, Douglas R, Mosca JD, et al. Multilineage potential of adult human mesenchymal stem cells. Science. 1999;284:143-7.

10. Roufosse CA, Direkze NC, Otto WR, Wright NA. Circulating mesenchymal stem cells. Int J Biochem Cell Biol. 2004;36: 585-97. http://dx.doi.org/10.1016/j.biocel.2003.10.007

11. Dicker A, Le Blanc K, Astrom G, van Harmelen V, Gotherstrom C, Blomqvist L, et al. Functional studies of mesenchymal stem cells derived from adult human adipose tissue. Exp Cell Res. 2005;308:283-90. http://dx.doi.org/10. 1016/j.yexcr.2005.04.029

12. Levi B, Longaker MT. Osteogenic differentiation of adiposederived stromal cells in mouse and human: In vitro and in vivo methods. J Craniofac Surg. 2010;22:388-91. http:// dx.doi.org/10.1097/SCS.0b013e318207b72b 
13. Levi B, Nelson ER, Brown K, James AW, Xu D, Dunlevie $\mathbf{R}$, et al. Differences in osteogenic differentiation of adiposederived stromal cells from murine, canine, and human sources in vitro and in vivo. Plast Reconstr Surg. 2010;128:373-86. http://dx.doi.org/10.1097/PRS.0b013e31821e6e49

14. Shih DT, Lee DC, Chen SC, Tsai RY, Huang CT, Tsai CC, et al. Isolation and characterization of neurogenic mesenchymal stem cells in human scalp tissue. Stem Cells. 2005;23:101220. http://dx.doi.org/10.1634/stemcells.2004-0125

15. Kawanabe N, Murata S, Murakami K, Ishihara Y, Hayano $\mathrm{S}$, Kurosaka $\mathbf{H}$, et al. Isolation of multipotent stem cells in human periodontal ligament using stage-specific embryonic antigen-4. Differentiation.79:74-83. http://dx.doi. org/10.1016/j.diff.2009.10.005

16. Yamada $\mathbf{Y}$, Fujimoto $\mathbf{A}$, Ito $\mathbf{A}$, Yoshimi $\mathbf{R}$, Ueda $\mathbf{M}$. Cluster analysis and gene expression profiles: A cDNA microarray system-based comparison between human dental pulp stem cells (hDPSCs) and human mesenchymal stem cells (hMSCs) for tissue engineering cell therapy. Biomaterials. 2006;27:3766-81. http://dx.doi.org/10.1016/j. biomaterials.2006.02.009

17. Dominici M, Le Blanc K, Mueller I, Slaper-Cortenbach I, Marini F, Krause D, et al. Minimal criteria for defining multipotent mesenchymal stromal cells. The International Society for Cellular Therapy position statement. Cytotherapy. 2006;8:315-7. http://dx.doi.org/10. $1080 / 14653240600855905$

18. Barry FP, Murphy JM. Mesenchymal stem cells: Clinical applications and biological characterization. Int J Biochem Cell Biol. 2004;36:568-84. http://dx.doi.org/10.1016/j.biocel. 2003.11.001

19. Hoogduijn MJ, Popp F, Verbeek R, Masoodi M, Nicolaou A, Baan C, et al. The immunomodulatory properties of mesenchymal stem cells and their use for immunotherapy. Int Immunopharmacol. 2010;10:1496-500. http://dx.doi. org/10.1016/j.intimp.2010.06.019

20. Chidgey AP, Layton D, Trounson A, Boyd RL. Tolerance strategies for stem-cell-based therapies. Nature. 2008;453: 330-7. http://dx.doi.org/10.1038/nature07041

21. Marigo I, Dazzi F. The immunomodulatory properties of mesenchymal stem cells. Semin Immunopathol. 2011;33:593602. http://dx.doi.org/10.1007/s00281-011-0267-7

22. Dazzi F, Krampera M. Mesenchymal stem cells and autoimmune diseases. Best Pract Res Clin Haematol. 2011;24:49-57. http://dx.doi.org/10.1016/j.beha.2011.01.002

23. Shanti RM, Li WJ, Nesti LJ, Wang $X$, Tuan RS. Adult mesenchymal stem cells: Biological properties, characteristics, and applications in maxillofacial surgery. $J$ Oral Maxillofac Surg. 2007;65:1640-7. http://dx.doi.org/10. 1016/j.joms.2007.04.008

24. Behnia $H$, Khojasteh A, Soleimani M, Tehranchi A, Khoshzaban A, Keshel SH, et al. Secondary repair of alveolar clefts using human mesenchymal stem cells. Oral Surg Oral Med Oral Pathol Oral Radiol Endod. 2009;108:e1-6. http:// dx.doi.org/10.1016/j.tripleo.2009.03.040

25. Aicher WK, Buhring HJ, Hart M, Rolauffs B, Badke A, Klein $\mathrm{G}$. Regeneration of cartilage and bone by defined subsets of mesenchymal stromal cells--potential and pitfalls. Adv Drug Deliv Rev. 2011;63:342-51. http://dx.doi. org/10.1016/j.addr.2010.12.004
26. National Institutes of Health. Clinicaltrials.gov. Fecha de consulta: junio de 2013. Disponible en: http://www. clinicaltrials.gov/ct2/results?term=mesenchymal+stem+cell s\&Search=Search.

27. Anitua E, Andia I, Ardanza B, Nurden P, Nurden AT. Autologous platelets as a source of proteins for healing and tissue regeneration. Thromb Haemost. 2004;91:4-15. http:// dx.doi.org/10.1267/THRO04010004

28. Illingworth KD, MusahI V, Lorenz S, Fu FH. Use of fibrin clot in the knee. Oper Tech Orthop. 2010;20:90-7. http:// dx.doi.org/10.1053/j.oto.2009.11.002

29. Schlag G, Redl H. Fibrin sealant in orthopedic surgery. Clin Orthop Relat Res. 1988;227:269-85.

30. Gibble JW, Ness PM. Fibrin glue: The perfect operative sealant? Transfusion. 1990;30:741-7.

31. Eyrich D, Brandl F, Appel B, Wiese H, Maier G, Wenzel M, et al. Long-term stable fibrin gels for cartilage engineering. Biomaterials. 2007;28:55-65. http://dx.doi.org/10.1016/j. biomaterials.2006.08.027

32. Mazlyzam AL, Aminuddin BS, Fuzina NH, Norhayati MM, Fauziah O, Isa MR, et al. Reconstruction of living bilayer human skin equivalent utilizing human fibrin as a scaffold. Burns. 2007;33:355-63. http://dx.doi.org/10.1016/j. burns.2006.08.022

33. Willerth SM, Arendas KJ, Gottlieb DI, Sakiyama-Elbert SE. Optimization of fibrin scaffolds for differentiation of murine embryonic stem cells into neural lineage cells. Biomaterials. 2006;27:5990-6003. http://dx.doi.org/10.1016/j. biomaterials.2006.07.036

34. Yamada Y, Boo JS, Ozawa R, Nagasaka T, Okazaki $\mathrm{Y}$, Hata $\mathrm{K}$, et al. Bone regeneration following injection of mesenchymal stem cells and fibrin glue with a biodegradable scaffold. J Craniomaxillofac Surg. 2003;31:27-33. http:// dx.doi.org/10.1016/S1010-5182(02)00143-9

35. Park KH, Kim H, Moon S, Na K. Bone morphogenic protein-2 (BMP-2) loaded nanoparticles mixed with human mesenchymal stem cell in fibrin hydrogel for bone tissue engineering. J Biosci Bioeng. 2009;108:530-7. http://dx.doi. org/10.1016/j.jbiosc.2009.05.021

36. Radosevich M, Goubran HI, Burnouf T. Fibrin sealant: Scientific rationale, production methods, properties, and current clinical use. Vox Sang. 1997;72:133-43. http://dx. doi.org/10.1046/j.1423-0410.1997.7230133.x

37. Standeven KF, Ariens RA, Grant PJ. The molecular physiology and pathology of fibrin structure/function. Blood Rev. 2005;19:275-88. http://dx.doi.org/10.1016/j.blre.2005. 01.003

38. Valbonesi M. Fibrin glues of human origin. Best Pract Res Clin Haematol. 2006;19:191-203. http://dx.doi.org/10.1016/j. beha.2005.01.009

39. Mokbel N, Naaman N, Nohra J, Badawi N. Healing patterns of critical size bony defects in rats after grafting with bone substitutes soaked in recombinant human bone morphogenetic protein-2: Histological and histometric evaluation. Br J Oral Maxillofac Surg. 2012;51:545-9. http:// dx.doi.org/10.1016/j.bjoms. 2012.08.005

40. Benlidayi ME, Tatli U, Kurkcu M, Uzel A, Oztunc H. Comparison of bovine-derived hydroxyapatite and autogenous bone for secondary alveolar bone grafting 
in patients with alveolar clefts. J Oral Maxillofac Surg. 2012;70:e95-e102. http://dx.doi.org/10.1016/j.joms.2011. 08.041

41. Chatterjea A, Meijer G, van Blitterswijk C, de Boer J. Clinical application of human mesenchymal stromal cells for bone tissue engineering. Stem Cells Int. 2010;2010:215625. http://dx.doi.org/10.4061/2010/215625

42. Sauerbier S, Rickert D, Gutwald R, Nagursky H, Oshima $\mathrm{T}$, Xavier SP, et al. Bone marrow concentrate and bovine bone mineral for sinus floor augmentation: A controlled, randomized, single-blinded clinical and histological trial-per-protocol analysis. Tissue Eng Part A. 2011;17:2187-97. http://dx.doi.org/10.1089/ten.TEA.2010.0516

43. Giannoudis PV, Einhorn TA, Schmidmaier G, Marsh D. The diamond concept--open questions. Injury. 2008;39(Suppl.2):S5-8. http://dx.doi.org/10.1016/S00201383(08)70010-X

44. Jones E, Yang X. Mesenchymal stem cells and bone regeneration: Current status. Injury. 2011;42:562-8. http:// dx.doi.org/10.1016/j.injury.2011.03.030

45. Hsiong SX, Mooney DJ. Regeneration of vascularized bone. Periodontol 2000. 2006;41:109-22. http://dx.doi.org/ 10.1111/j.1600-0757.2006.00158.x

46. Cancedda R, Giannoni P, Mastrogiacomo M. A tissue engineering approach to bone repair in large animal models and in clinical practice. Biomaterials. 2007;28:4240-50. http://dx.doi.org/10.1016/j.biomaterials.2007.06.023

47. Levi B, Longaker MT. Concise review: Adipose-derived stromal cells for skeletal regenerative medicine. Stem Cells. 2011;29:576-82. http://dx.doi.org/10.1002/stem.612

48. Beltran O. Expresión de factores angiogénicos en células madre mesenquimales humanas derivadas de tejido adiposo, en condiciones de normoxia e hipoxia (tesis). Bogotá: Universidad Nacional de Colombia; 2007.

49. Zuk PA, Zhu M, Ashjian P, De Ugarte DA, Huang J, Mizuno $\mathbf{H}$, et al. Human adipose tissue is a source of multipotent stem cells. Mol Biol Cell. 2002;13:4279-95. http://dx.doi.org/10.1091/mbc.E02-02-0105

50. Lee RH, Kim B, Choi I, Kim H, Choi HS, Suh K, et al. Characterization and expression analysis of mesenchymal stem cells from human bone marrow and adipose tissue. Cell Physiol Biochem. 2004;14:311-24. http://dx.doi.org/10. $1159 / 000080341$

51. Lowe J. Histotechnology technical methods enzyme histochemical stain. Fecha de consulta: junio de 2013. Disponible en: www.nottingham.ac.uk/pathology/protocols/ alkphos.html
52. Fink T, Abildtrup L, Fogd K, Abdallah BM, Kassem M, Ebbesen $\mathrm{P}$, et al. Induction of adipocyte-like phenotype in human mesenchymal stem cells by hypoxia. Stem Cells. 2004; 22:1346-55. http://dx.doi.org/10.1634/stemcells. 2004-0038

53. Linnes MP, Ratner BD, Giachelli CM. A fibrinogen-based precision microporous scaffold for tissue engineering. Biomaterials. 2007;28:5298-306. http://dx.doi.org/10.1016/j. biomaterials.2007.08.020

54. Prophet EB, Mills B, Amington JB, Sobin LH. Methods in Histotechnology. Washington, D.C.: Armed Forces Institute of Pathology Laboratory; 1992.

55. Mesimaki K, Lindroos B, Tornwall J, Mauno J, Lindqvist C, Kontio R, et al. Novel maxillary reconstruction with ectopic bone formation by GMP adipose stem cells. Int J Oral Maxillofac Surg. 2009;38:201-9. http://dx.doi.org/10.1016/j. ijom.2009.01.001

56. Meijer GJ, de Bruijn JD, Koole R, van Blitterswijk CA. Cell based bone tissue engineering in jaw defects. Biomaterials. 2008;29:3053-61. http://dx.doi.org/10.1016/j. biomaterials.2008.03.012

57. Krampera M, Glennie S, Dyson J, Scott D, Laylor R, Simpson E, et al. Bone marrow mesenchymal stem cells inhibit the response of naive and memory antigen-specific T cells to their cognate peptide. Blood. 2003;101:3722-9. http://dx.doi.org/10.1182/blood-2002-07-2104

58. Gimble JM, Katz AJ, Bunnell BA. Adipose-derived stem cells for regenerative medicine. Circ Res. 2007;100:1249-60. http://dx.doi.org/10.1161/01.RES.0000265074.83288.09

59. Monaco E, Bionaz M, Hollister SJ, Wheeler MB. Strategies for regeneration of the bone using porcine adult adiposederived mesenchymal stem cells. Theriogenology.75:138199. http://dx.doi.org/10.1016/j.theriogenology.2010.11.020

60. Stewart MC, Stewart AA. Mesenchymal stem cells: Characteristics, sources, and mechanisms of action. Vet Clin North Am Equine Pract. 2011;27:243-61. http://dx.doi. org/10.1016/j.cveq.2011.06.004

61. Pittenger MF, Mosca JD, Mclntosh KR. Human mesenchymal stem cells: Progenitor cells for cartilage, bone, fat and stroma. Curr Top Microbiol Immunol. 2000;251:3-11. http://dx.doi.org/10.1007/978-3-642-57276-0_1

62. Kolf CM, Cho E, Tuan RS. Mesenchymal stromal cells. Biology of adult mesenchymal stem cells: regulation of niche, self-renewal and differentiation. Arthritis Res Ther. 2007;9:204. http://dx.doi.org/10.1186/ar2116 